\title{
Micromole per Milligram per Minute
}

National Cancer Institute

\section{Source}

National Cancer Institute. Micromole per Milligram per Minute. NCI Thesaurus. Code C73735.

A unit of concentration (molarity unit) equal to one millionth of a mole (10E-6 mole) per milligram of a substance per period of time equal to sixty seconds. 